\title{
The Impact Of Core Job Dimensions On Satisfaction And Performance: A Test In An International Environment
}

\author{
Raed Awamleh, (Email: RaedAwamleh@uowdubai.ac.ae), University of Wollongong in Dubai, UAE
} Cedwyn Fernandes, University of Wollongong in Dubai, UAE

\begin{abstract}
This study tested core dimensions of the Job Characteristics Model among non-managerial employees at functional levels in United Arab Emirates (UAE) banks. The UAE banking sector was chosen due to its importance in the U.A.E. economy and its significant contribution to the Emirates $G D P$. The paper examines the effects of core job dimensions on both affective responses represented by satisfaction, and behavioral responses represented by performance. Core job dimensions are skill variety, task identity, task significance, autonomy, and feedback. Data was collected from employees working in national and international banks operating in the UAE. Regression analyses revealed that contrary to expectations, satisfaction was not related to the core job dimensions while performance was. Furthermore, results in this case seem not to support the view that the core dimensions are related to affective responses but not behavioral ones. Evidence suggests that banks in the UAE will benefit by actively looking into the impact of job design and by training their managers to acquire job redesign skills. Furthermore, there might be added value in terms of performance of employees if banks refine the process by which they design tasks and jobs. Moreover, results above are discussed while implications and future research directions are outlined.
\end{abstract}

\section{INTRODUCTION}

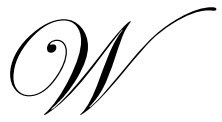

ork design models have attracted considerable research attention (e.g., Ambrose \& Kulik, 1999; Parker, Wall \& Corderly, 2001). It is believed that the design of work has a remarkable impact on organizational success and on key individual outcomes and general well being (Oldham, 1996; Morgeson \& Campion, 2003). The original works of Maslow, McGregor, and Herzberg all emphasized the importance of work design to organizations and as a source of work motivation. Indeed, Herzberg's Two Factor theory gave grounds for Hackman and Oldham (1980) to initiate their Job Characteristics Model which has received a lot of research interest since its inception with mixed empirical support. Practitioners have also recognized the centrality of work design in their effort to increase efficiency, satisfaction, and performance. Indeed, a major part of every manger's job is designing the work of employees.

Critical organizational outcomes have been associated with work design elements. However, debate among researches is active in terms of what outcomes are really determined by work design. More specifically, it seems to be accepted by researchers that the various job dimensions have their most significant effects on intrinsic motivation and satisfaction, while the effects on actual work behaviors such as performance and turnover are not well established (Ambrose \& Kulik, 1999).

Accordingly, the current study aims to further address the above concern. Specifically, this paper will test the impact of core job dimensions on satisfaction (affective response) and performance (behavioral response) of banking non managerial employees in the UAE. Despite the wide research interest, it seems that the banking environment did 
not receive adequate attention from work design research. So, another key objective of this study is to fill this knowledge gap. Accordingly, the study is designed to assess the effects of the five core job dimensions according to Hackman and Oldham on UAE bank employees' self-perceived performance and job satisfaction.

\section{THE JOB CHARACTERISTICS MODEL}

The idea of division of labor by breaking down complex tasks into smaller ones in order to increase efficiency and performance is not new as it was promoted by Adam Smith, while implemented and refined by many others namely Fredrick Taylor and the school of scientific management. One of the more recent approaches to work design at the individual job level is the Job Characteristics Model advanced by Hackman and Oldham (1976). They believed that identifying characteristics that make jobs intrinsically motivating would also allow for specifying the consequences of those characteristics. Ultimately, the model identified five "core job characteristics". These are:

- $\quad$ Skill Variety: the degree to which a job requires a worker to use different skills, abilities, or talents;

- $\quad$ Task Identity: the degree to which a job involves performing a whole piece of work from start to finish;

- Task Significance: the degree to which a job has an impact on the lives or work of other individuals;

- $\quad$ Autonomy: the degree to which a job allows a worker the freedom and independence to schedule work and decide how to carry it out;

- $\quad$ Feedback: the degree to which performing a job provides a worker with clear information about his or her effectiveness.

The model goes on to specify the above five core job characteristics as determinants of three "critical psychological states". These are Experienced Meaningfulness, Experienced Responsibility, and Knowledge of Results. In turn, the specified critical physiological states will lead to higher internal work satisfaction, high quality performance, high satisfaction with the work, and lower absenteeism and turnover.

Again, the Job Characteristics Model attracted much attention as more than two hundred studies were published while examining its different aspects. However, much debate surrounds its various elements such as affective versus behavioral responses, the validity of growth-need strength as a moderating variable, and the effect of social cues and perceived equity (e.g., Tiegs, Tetrick, \& Fried, 1992; Johns, Xie, \& Fang, 1992).

\section{THE BANKING ENVIRONMENT IN THE UAE}

The UAE banking system is unique from other banking systems within the Arab and non-Arab world. First, it is highly congested. For a relatively small population of approximately three million, the UAE tends to have a large number of banks as well as bank branches. The UAE population consists of $80 \%$ expatriates and $20 \%$ indigenous population. Currently the UAE has 49 national and foreign banks. In terms of bank branches, domestic banks have a total of 263 branches or an average of 12 per bank. Foreign banks on the other hand are limited to a maximum of eight branches per bank. Currently, there are 106 branches of foreign banks or an average of 4 branches per bank. In addition to this there are 45 representative offices of foreign banks. The large number of banks in the UAE has led to a branch density of 12.8 branches for every 100,000 people. If one compares the number of banks and bank branches with UAE nationals then it has the highest levels of bank congestion in the world.

The banking sector in many countries has undergone considerable development and is now a mature industry with established styles of management and leadership. This is not the case with banking in the UAE which is relatively young compared to other countries. Nonetheless, the banking sector is well capitalized and profitable. The financial sector in the UAE in general is underlined by a solid legal framework and judicial system.

\section{PROBLEM DEFINITION}

This study aims at addressing key questions by examining the Job Characteristics Model in terms of satisfaction (affective response) and performance (behavioral response) in a banking setting. As shown earlier, 
research results are not conclusive on the consequences of the five core dimensions especially with relevance to the different types of responses, affective and behavioral. In addition, this study will examine the model in a relatively new territory, banks. Banks in general have strict rules and procedures of operations, especially compared with other sectors. This would be expected in a business where mistakes can be extremely costly. One would expect this limitation to restrict the degree of flexibility in designing jobs in banks and accordingly greatly influence the personal and work outcomes (e.g., empowering loan officers to push the limits on loans or advances). Accordingly, this study is concerned with testing the impact of the five core dimensions on both satisfaction and performance. In order to address the specific gaps and questions in research, this study focuses only on the above factors in the model and handles them separately and does not attempt to test the whole model.

\section{HYPOTHESES}

Based on the review of the literature and the general discussion, the following two hypotheses are advanced:

H1: There is a significant positive relationship between the five core dimensions and bank employees' job satisfaction.

H2: There is no significant relationship between the five core dimensions and self-perceived performance.

\section{METHOD}

\section{Population, Sample, And Subjects}

A total of 815 questionnaires were distributed to banks operating in the United Arab Emirates. The number of questionnaires delivered to each bank was determined by the size of its workforce. The target population was full-time bank employees, working in non-managerial positions. The questionnaire included a total of 41 items. From the questionnaires distributed, two hundred and forty seven questionnaires were collected, of which 13 were excluded due to incomplete data. The final sample consisted of 194 respondents, representing 7 banks.

The majority of the respondants hold Bachelor degrees, were males aged between 25 to 40 years of age and on average had been employed by the Bank for 5 years. India, UAE and Pakistan were the dominant countries of origin.

\section{Measures}

The Job Diagnostic Survey (JDS) developed by Hackman and Oldham (1980) was used to measure subjects' perceptions of the core five job dimensions. The JDS consists of 15 items. The JDS is well known in literature and is widely used, it validity and reliability are established (e.g., Ambrose \& Kulik, 1999).

The study adopted two instruments to measure the dependent variables developed in a previous study (AlDmour, \& Awamleh, 2002). Job satisfaction was assessed by a 14-item scale covering areas normally tapped in organizational behavior research. Examples of items include, "In general, I am satisfied with work", and "I find that my opinions are respected at work". The self-assessed performance scale comprised of 5 items, such as, "I consider my performance better than the average person in my company", and "I always reach my work targets".

\section{RESULTS}

\section{Scale Reliabilities}

As a first step, scale reliability coefficients (Cronbach Alphas) for all measures adopted in this study were computed. Nunnally (1978) maintains that reliabilities which are less than 0.6 are considered poor, those in the 0.7 range are acceptable, while those above 0.8 are good. Results showed that reliability for job satisfaction scale is 0.72 , while performance scored 0.75 . Reliability for JDS was 0.74 . 


\section{Correlations}

Intercorrelations among all variables used in this study are summarized in Table 1. As desired when running regression analyses, the dependent variables show low correlation with each other $(r=0.25, p<0.001)$, although it is significant. It is interesting, however, to see the extremely low correlations between all five dimensions and satisfaction which seems to be, at least at this stage, contrary to expectations. Meanwhile, self-perceived performance is significantly and moderately correlated with all five dimensions. The highest correlation obtained $(r=0.43, p<$ 0.001 ) is between Autonomy and Feedback.

\section{Table 1: Intercorrelations Of All Variables}

\begin{tabular}{|c|c|c|c|c|c|c|}
\hline & 1 & 2 & 3 & 4 & 5 & 6 \\
\hline 1. Satisfaction & & & & & & \\
\hline 2. Performance & $0.25 * *$ & & & & & \\
\hline 3. Skill Variety & 0.26 & $0.26 * *$ & & & & \\
\hline 4. Task Identity & 0.05 & $0.25 * *$ & 0.11 & & & \\
\hline 5. Task Significance & 0.02 & $0.35 * *$ & $0.15 *$ & $0.34 * *$ & & \\
\hline 6. Autonomy & 0.07 & $0.34 * *$ & $0.19 * *$ & $0.33 * *$ & $0.25 * *$ & \\
\hline 7. Feedback & 0.02 & $0.36 * *$ & $0.22 * *$ & $0.39 * *$ & $0.39 * *$ & $0.43 * *$ \\
\hline
\end{tabular}

**correlation is sig. at $\mathrm{p}<0.01 ; *$ correlation is sig. at $\mathrm{p}<0.05$

\section{Hypotheses Testing: Multiple Regression}

Two multiple regression models were run to test the two hypothesis. Table 2 shows results of the multiple regression with satisfaction as the dependent variable and the five core dimensions as independent variables. Surprisingly, the overall model is not significant, neither is any of the other relationships. This goes against our expectations based on the general body of research in this area and will require further exploration which will be provided in the discussion section.

Table 2: Multiple Regression, Job Satisfaction Is Dependent Variable

Dependent Variable: Satisfaction

Multiple R: 0.118, R Square: 0.0124, Adjusted R Square: 0.012, Standard Error: 0.67912

Analysis Of Variance

$\begin{array}{lll} & \text { DF } & \text { Mean Square } \\ \text { Regression } & 5 & 0.244 \\ \text { Residual } & 187 & 0.461\end{array}$

F: 0.530, Sig. F: 0.753

Variables In The Equation

$\begin{array}{llllll}\text { Variable } & \text { B } & \text { SE } & \text { Beta } & \text { T } & \text { Sig. T } \\ \text { Skill Variety } & \text { 6.75E-03 } & 0.032 & 0.016 & 0.210 & 0.834 \\ \text { Task Identity } & 4.397 \mathrm{E}-02 & 0.040 & 0.091 & 1.112 & 0.268 \\ \text { Task Sig. } & 1.206 \mathrm{E}-02 & 0.041 & 0.024 & 0.291 & 0.771 \\ \text { Autonomy } & 4.98 \mathrm{E}-02 & 0.042 & 0.098 & 1.184 & 0.238 \\ \text { Feedback } & 1.38 \mathrm{E}-02 & 0.046 & 0.026 & 0.299 & 0.765\end{array}$


$\begin{array}{lllrr}\text { (Constant) } & 2.548 & 0.256 & 9.619 & 0.000\end{array}$

Results of the second multiple regression are shown in Table 3. The dependent variable was self-perceived performance, and the five core dimensions as independent variables. Unlike the first test, and contrary to our expectations the overall model is significant at $p<0.001$. Except for Task Identity, all core dimensions are related significantly to performance. The results of both regression analyses are indeed intriguing and will be addressed in the discussion section.

Table 3: Multiple Regression, Self-Perceived Performance Is Dependent Variable

\section{Dependent Variable: Performance}

Multiple R: 414, R Square: 0.244, Adjusted R Square: 0.224, Standard Error: 0.53763

Analysis Of Variance

$\begin{array}{llll} & \text { DF } & \text { Sum of Squares } & \text { Mean Square } \\ \text { Regression } & 5 & 17.422 & 3.484 \\ \text { Residual } & 187 & 54.052 & 0.289 \\ & & & \\ \text { F: } 12.055, & \text { Sig. F: } 0.0000 & & \end{array}$

Variables In The Equation

$\begin{array}{llllll}\text { Variable } & \text { B } & \text { SE } & \text { Beta } & \text { T } & \text { Sig. T } \\ \text { Skill Variety } & \text { 6.02E-02 } & 0.025 & 0.155 & 2.364 & 0.019 \\ \text { Task Identity } & 0.315 & 0.031 & 0.051 & 0.710 & 0.479 \\ \text { Task Sig. } & 5.998 \mathrm{E}-03 & 0.033 & 0.205 & 2.886 & 0.004 \\ \text { Autonomy } & 0.261 & 0.033 & 0.180 & 2.490 & 0.014 \\ \text { Feedback } & 7.32 \mathrm{E}-02 & 0.037 & 0.154 & 2.004 & 0.046 \\ \text { (Constant) } & 3.535 & 0.210 & & 16.859 & 0.000\end{array}$

\section{DISCUSSION}

Our results show that the five core job dimensions of skill variety, task identity, task significance, autonomy, and feedback do not show any impact on job satisfaction. This directly means rejecting Hypothesis one. The original premise in this hypothesis was based on research results that generally confirm such a relationship with affective responses such as satisfaction. Furthermore, and based on the assertion that the core dimensions do not relate well in prior research to behavioral responses including performance, we hypothesized that there will not be that relationship in the current study. Surprisingly again, results showed the opposite of what we predicted. Indeed, in this study, all of the core job dimensions, except for task identity came out as significantly related to performance. This means that these factors can predict on the job performance (albeit the self assessed/perceived performance in this case).

Again, findings of this study do not conform to the general beliefs and findings regarding affective and behavioral responses. Bank employees in this case do not seem to get any satisfaction from the existence, or absence, of core job dimensions which is not only counterintuitive but also contrary to most research evidence. Bank employees in this case seem to respond much more positively in terms of performance. Perhaps in this case (banking and multicultural environments) employees feel more comfortable with a work system that defines their tasks and clearly spells out performance targets and expectations thereby making patent performance-reward linkages. Moreover, it is possible that redesigning jobs to include the core dimensions in a bank environment where the majority of tasks are highly standardized and routinized is not a straightforward process. However, when we add to the picture the result of the second hypothesis, it gets much less straightforward. 
Performance in this case is related to skill variety, task significance, autonomy, and feedback, but not task identity. This is another interesting result. It seems that bank employees perceive the above four dimensions as drivers for performance. They guide them and allow the work flow to ensure results which is recognized by them, although they do not see that as a source of satisfaction. This last conclusion about satisfaction-performance relationship is in itself intriguing in light of the body of research which asserts that satisfaction follows performance. Again, not so in this case. Satisfaction in such a heavy expatriate environment could be related more to extrinsic motivation factors such salaries, benefits, contract renewals, etc.

Why was task identity in particular not related to performance? This seems to also be another sector specific result. One can see that bank tasks are complex and highly interrelated providing little chance for task identity to be highlighted, especially in the non managerial level. Task identity is all about performing a whole piece of work from beginning to end. At an operational employee level in a bank this may not be likely. In all cases, it is unclear at this point whether or not different results obtained in this study are a result of the specific sector under study (banking) or cultural, or both with possible influence of other factors. Further and deeper investigation is required in order to make stronger statements about results. In that sense, the current study can be considered exploratory.

\section{Future Research Direction}

Results of this study open the door widely for further investigations. Areas deserving serious attention include the relationship between satisfaction and performance while empirically exploring assertions made in the discussion section about the nature of tasks in banks as they relate to the core dimensions. In addition, this study used selfperceived performance which is a limitation and it would be of value to try to independently measure performance. Also worthy of scholarly attention is the assessment of effects that experience, level of skills, career aspirations have on perceptions of satisfaction and performance. In addition, the satisfaction relationship should be further explored. For example, how would task structure, position power, and group norms impact satisfaction in banks. In this regard, the UAE is a fertile ground where a very large percentage of the labor force is expatriate. Such a study will become even more relevant in light of the nationalization policy that the government is implementing (Emaritaization). This environment presents promising opportunities for cultural studies as they relate to models such as the job characteristics model.

\section{CONCLUSION}

Results of this study provided alternative views to the some of the dominant ones in literature surrounding the job characteristics model in general and core job dimensions in particular. Research in this area generally accepts the assertion that the core job dimensions give rise to affective responses and not behavioral ones (e.g., Ambrose \& Kulik, 1999). This study suggests that perhaps there is room for some modified views. As discussed earlier, these intriguing results allow for different interpretations, however, they also call for considerable further studies designed in ways that allow for reaching more concrete conclusions.

So far as the evidence at this early stage suggests, banks in the UAE will benefit by actively looking into the impact of job design by training their managers to acquire job redesign skills. There might be added value in terms of performance of employees if banks refine the process by which they design tasks and jobs.

\section{REFRENCES}

1. Ambrose, M. L and Kulik, C. T. (1999). Old Friends, New Faces: Motivation Research in the 1990s, Journal of Management, 25(3), pp 231-292.

2. Parker, S. K, Wall, T. D., and Corderly, J. L. (2001). Future work Design Research and Practice: Towards an Elaborated Model of Work Design, Journal of Occupational and Organizational Psychology, 74, pp 413440.

3. Oldham, G. R. (1996). Job Design, In International Review of Industrial Psychology, 11. Cooper, C. L. and 
Robertson, I. T (Eds), Wiley.

4. Morgeson, F. R. and Campion. (2003). In Handbook of Psychology, 12, pp. 425-452. W. C. Borman, D. R.

Ilgen, and R. J. Klimoski (Eds).

5. Hackman, J. R. and Oldham, G. R. (1980). Work redesign. Reading, Mass: Addison-Wesley.

6. Hackman, J. R. and Oldham, G. R. (1976). Motivation Through the Design of Work: Test of a Theory, Organizational Behavior and Human Performance, pp. 250-79.

7. Tiegs, R. B., Tetrick, L. E, and Fried, Y. (1992). Growth Need Strength and Context Satisfactions as Moderators of the Relations of the Job Characteristics Model, Journal of Management, pp 575-93.

8. Johns, G., Xie, J. L., and Fang, Y. (1992). Mediating and Moderating Effects in Job Design, Journal of Management, pp. 657-76.

9. Al-Dmour, H. and Awamleh, R. (2002). Effects of Transactional and Transformational Leadership Styles of Sales Managers on Job Satisfaction and Self-Perceived Performance of Sales People: A study of Jordanian Manufacturing Public Shareholding Companies, Dirasat: Administrative Sciences Series, 29(1): 247-261.

10. Nunnally, J. C. (1978). Psychometric theory. New York: McGraw-Hill.

\section{NOTES}




\section{NOTES}

